This item was submitted to Loughborough's Research Repository by the author.

Items in Figshare are protected by copyright, with all rights reserved, unless otherwise indicated.

\title{
Processing of collagen gels to create in vitro cell growth matrix without damage to the collagen native structure
}

PLEASE CITE THE PUBLISHED VERSION

PUBLISHER

Professional Engineering Publishing / @ IMechE

VERSION

VoR (Version of Record)

LICENCE

CC BY-NC-ND 4.0

\section{REPOSITORY RECORD}

Liu, Yang, and David J. Williams. 2019. "Processing of Collagen Gels to Create in Vitro Cell Growth Matrix Without Damage to the Collagen Native Structure". figshare. https://hdl.handle.net/2134/4708. 
This item was submitted to Loughborough's Institutional Repository (https://dspace.lboro.ac.uk/) by the author and is made available under the following Creative Commons Licence conditions.

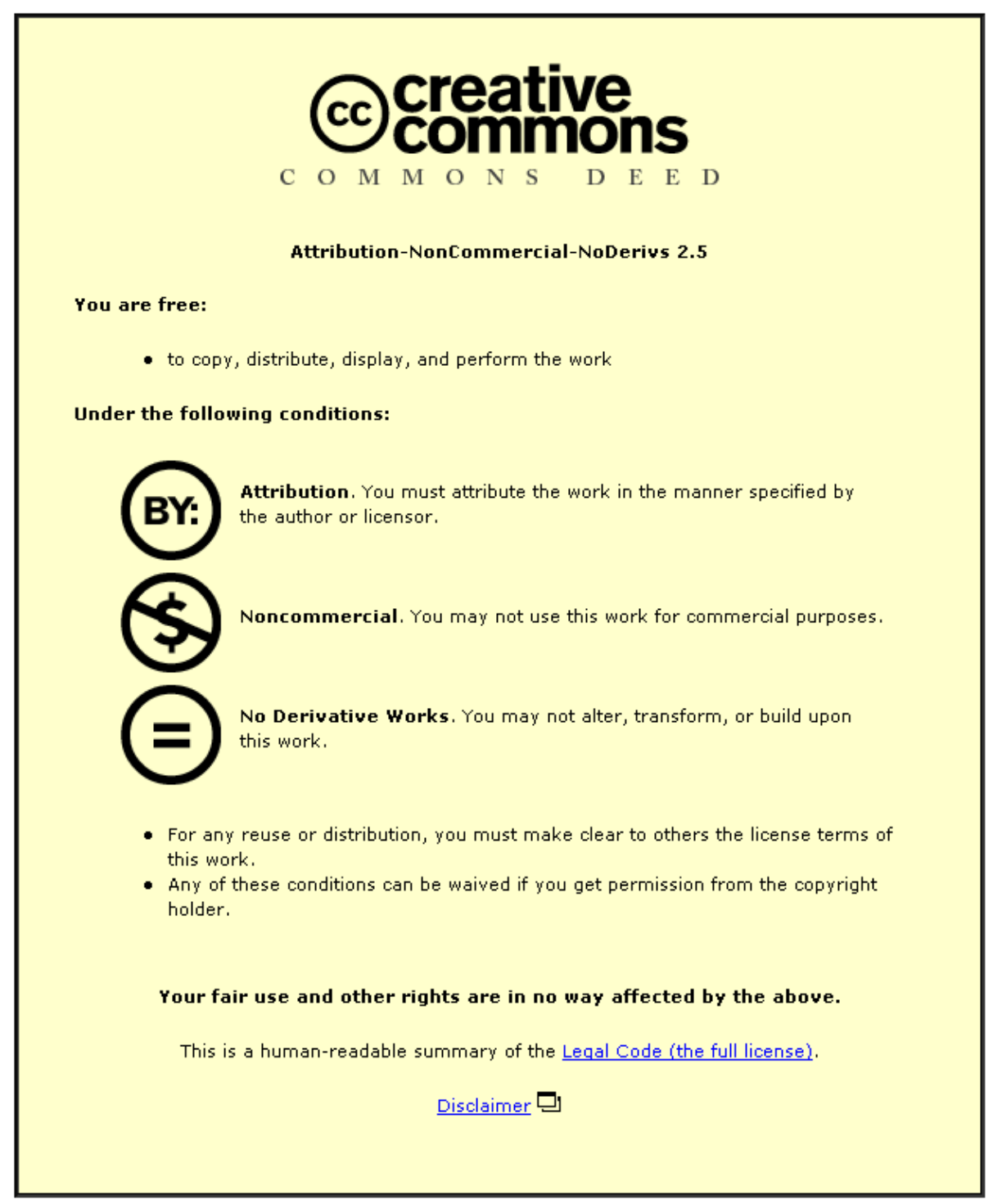

For the full text of this licence, please go to: http://creativecommons.org/licenses/by-nc-nd/2.5/ 


\title{
Processing of collagen gels to create in vitro cell growth matrix without damage to the collagen native structure
}

\author{
Yang Liu and D J Williams* \\ Wolfson School of Mechanical and Manufacturing Engineering, Loughborough University, LE11 3TU
}

The manuscript was received on 27 May 2005 and was accepted after revision for publication on 8 November 2005.

DOI: 10.1243/09544054JEM392SC

\begin{abstract}
This preliminary work explores a technique for processing collagen gels to provide a structured matrix support for cell growth and other tissue engineering applications without using cyto-toxic photo-initiators. Collagen gels can be structured by techniques similar to those of rapid manufacturing and retain the fibril structure of native collagen. Incorporation of alpha-modified minimal essential medium (MEM) in the collagen solution improved the rate of gelation in a cell-friendly way. Local gelation of a collagen solution formulated with alpha-modified MEM can be achieved by exposure to radiation from a remote incandescent lamp source indicating that it may be possible to prepare structured gels by lithographically based rapid manufacturing processes. Exposure of the alpha-modified MEM collagen solution to the radiation also increased the thickness of the collagen fibrils formed during the gelation process to create a more structured gel. Methyl blue staining, scanning electron microscope (SEM), and differential scanning calorimetry (DSC) experiments confirmed the collagen was not denatured, i.e. the native structure of collagen was retained.
\end{abstract}

Keywords: cell culture matrix, collagen, gel, tissue engineering

\section{INTRODUCTION}

Collagen is the main component of organic extracellular matrix (ECM). In vivo, the structure and spatial arrangement of collagen fibres, together with additional proteins, polysaccharides, and water, facilitates the biological activities of embedded cells [1] It is well known that the native structure promotes cell growth, modifies adhesion and migration and, in certain cell types, even promotes cell differentiation $[1,2]$ in vitro. The authors wish to generate a cell-friendly, structured collagen matrix for potential applications in tissue engineering.

Early work by Bell et al. [3], aimed at incorporating cells in collagen gels, observed that it was necessary rapidly to mix cells with the collagen as it was found that the gelation time of the neutralized collagen solution was reduced when mixed with McCoy's

*Corresponding author: Wolfson School of Mechanical and Manufacturing Engineering, Loughborough University, Ashby Road, Loughborough LE11 3TU, UK. email: d.j.williams@ lboro.ac.uk cell culture medium. More recently, Besseau et al. [4], when incorporating fibroblasts in a collagen gel with Eagle-modified minimal essential medium (MEM) for cell culture, commented on gelation in 'a few minutes'. The present study seeks to exploit these observations. Alpha-modified MEM, a cellfriendly and non-toxic material, currently commercially available for use for cell support and nutrient supply during cell culture, was investigated to establish whether it could promote collagen gelation. This preliminary work also explored the processing of collagen gels to provide a structured matrix support for cell growth and other tissue-engineering applications in a similar manner to established lithographiclike rapid prototyping techniques but without using a cyto-toxic photo-initiator. The aim of the present work is to identify a method to promote and control the site of collagen gelation while retaining the native structure of collagen. Ultimately, this technique may be applicable for the construction of a structured collagen gel capable of providing an environment that assists cell growth and permits the inclusion of cells into a structure of controlled dimensions. 


\section{RATIONALE}

The stability of collagenous substrates or implants is dependent mainly on the extent of cross-linking between collagen molecules and microfibrils [5]. Much effort has focused on the enhancement of the biological stability of collagen, generally based on chemical (glutaraldehyde) or physical (dehydrothermal) treatments of collagenous tissue for use in prostheses. However, in spite of improving the stability of the collagenous matrix, these treatments damage of (denature) the native structure of the collagen within the matrix because of the chemical or physical stresses involved in processing [2]. For instance, in overheating a collagen formulation above its denaturation temperature [6], when the denaturation temperature is exceeded, the collagen loses much of its native structure and consequentially is less able to promote cell growth.

Many of the collagen sponges used as substrata for cell culture in tissue engineering have been prepared by lyophilization (freeze drying). Since the macroscopic structure is dependent upon the phase transition from water to ice, it is difficult to control the structural parameters of these sponges, such as porosity and connectivity, which are critical to the biological behaviour of cells loaded within the structure and at their implantation site.

Recent studies emphasize the importance of introducing the concepts of manufacture into tissue engineering and scaffold generation $[\mathbf{7}, \mathbf{8}]$. The similarity between the physico-chemical properties of collagen and thermally polymerized polymer indicate that conventional rapid prototyping techniques may be modified and adapted to three-dimensional collagen scaffold generation. The main barriers to the application of such techniques are the length of time for collagen gelation and the problem of localizing the site of gelation. Attempts have been made to overcome these barriers by introducing photopolymerization into the gelation process, but this has tended to reduce the denaturation temperature of collagen. For instance, modification of a collagen formulation with photo-cross-linkable methacrylamide groups reduces the denaturization temperature from 39 to $36{ }^{\circ} \mathrm{C}$ [9]. As cell growth proceeds optimally at $37^{\circ} \mathrm{C}$, this is not therefore well suited for cell growth. In addition, although cells included in photo-cross-linked gels during polymerization remained viable, the photo-initiators were cyto-toxic and reduced the proliferation rate of incorporated cells [10].

The present work explores the opportunities of generating a structured collagen gel with improved cell-friendly properties in a manner that is potentially exploitable within a photolithographically based rapid prototyping process.

\section{METHODOLOGY AND RESULTS}

Collagen solutions (collagen type I obtained from rat tail tendon: $\mathrm{BD}$ Biosciences, Cowley, UK) were formulated with an alpha-modified minimum essential medium (alpha-modified MEM, M0894: Sigma, Dorset, UK) or phosphate buffered saline (PBS: Sigma, Dorset, UK).

Collagen is supplied in a concentrated acidic solution $(3.14 \mathrm{mg} / \mathrm{ml})$. Neutralized collagen solutions of concentrations up to $2 \mathrm{mg} / \mathrm{ml}$ have been found to be effective in the preparation of gels for cell culture, particularly for maintaining the subsequent behaviour of loaded cells [11] and giving appropriate mechanical properties to the resulting gel [12]. PBS is used conventionally to prepare collagen gels; consequently, this was used as a comparator. An alkaline solution was prepared by adding $1 \mathrm{M} \mathrm{NaOH}$ $(0.15 \mathrm{ml})$ to alpha-modified MEM $(3.33 \mathrm{ml})$ with an osmolality in the range 284-314 $\mathrm{mOsm} / \mathrm{kg} \mathrm{H} \mathrm{H}_{2} \mathrm{O}$. In order to prepare the comparator, the same volume of sodium hydroxide solution was added to a PBS solution of equivalent osmolality to the alphamodified MEM. Both solutions were used to neutralize and dilute $6.41 \mathrm{ml}$ of acidic collagen solution to a concentration of $2 \mathrm{mg} / \mathrm{ml}$ of collagen. Note that this gives a collagen alpha-modified MEM solution with approximately $10 \mathrm{mg} / \mathrm{ml}$ of alphamodified MEM. The $\mathrm{pH}$ of the collagen solutions was adjusted to 7.4 by the addition of $0.1 \mathrm{M} \mathrm{NaOH}$. Distilled water was added to bring the collagen solutions to a final volume of $10 \mathrm{ml}$. The collagen solutions were stored on ice to prevent gel formation.

A quantity of $5 \mathrm{~mm}$ of collagen PBS solution or collagen alpha-modified MEM solution was added to a $60 \mathrm{~mm}$ diameter cell culture Petri dish to cover its base to a thickness of approximately $5 \mathrm{ml}$. Gelation was induced by exposing the Petri dish to the radiation from an incandescent filament lamp $(60 \mathrm{~W})$, placed at a distance of approximately $10 \mathrm{~cm}$, or by placing it in a water bath $\left(37^{\circ} \mathrm{C}\right)$. The latter is equivalent to the conventional process for gel preparation in a $37{ }^{\circ} \mathrm{C}$ incubator [13]. The Petri dish was tilted at $4 \mathrm{~min}$ intervals to test whether gelation had taken place. Flow was taken as an indicator that gelation had not taken place. Once gelation had taken place, the excess solution was removed. A thermometer placed adjacent to the Petri dish was used to evaluate the temperature of the exposed surface of collagen solution. To achieve localized gelation, part of the Petri dish surface was covered by aluminium foil throughout the exposure to the 

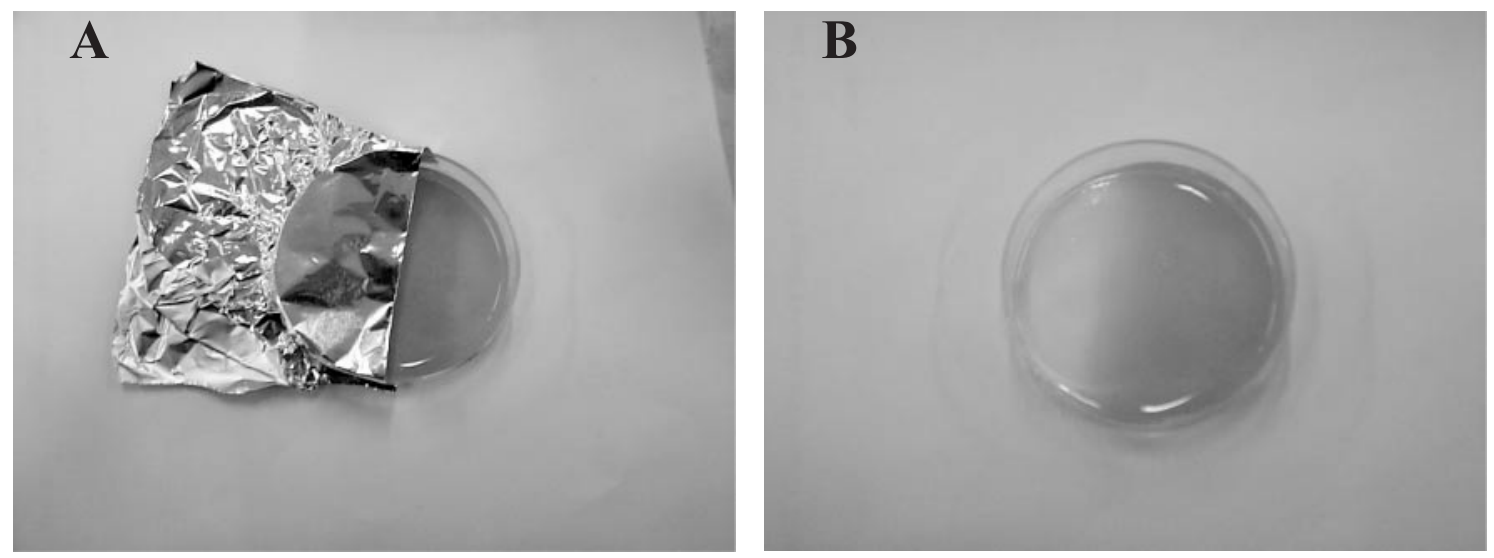

Fig. 1 (a) Part of the surface of the Petri dish containing collagen alpha-modified MEM solution was covered by foil before exposure to the radiation from an incandescent filament; (b) shows a lack of gelation in the previously covered area of the dish (diameter of Petri dish $60 \mathrm{~mm}$ )

incandescent lamp to create an exposed/unexposed boundary.

The collagen alpha-modified MEM solution (collagen concentration of $2 \mathrm{mg} / \mathrm{ml}$ ) began to form a gel after about $10 \mathrm{~min}$ exposure to the radiation from an incandescent filament at a surface temperature of approximately $35{ }^{\circ} \mathrm{C}$. Gelation was observed on the exposed surface of the part-covered Petri dish, with a gradient edge at the interface between the covered and uncovered surface (Figs 1(a) and (b)). Gradient formation is likely to result from the effects of the gap between the foil and solution surface and heat transfer into the covered portion. In contrast, the collagen PBS solution (collagen concentration of $2 \mathrm{mg} / \mathrm{ml}$ ) began to form a gel after about $25 \mathrm{~min}$ exposure to the radiation from an incandescent filament. No gradient edge can be formed using the water bath.

In order to prepare the gels for scanning electron microscope (SEM) examination they were dehydrated in a series of graded concentrations of ethanol ranging from 10 to 100 per cent. The dehydrated samples were dried further in hexamethyl disilazan (Sigma, Dorset, UK) at room temperature. SEM examination of the dehydrated gel samples showed that the structure of the gel and size of the collagen fibrils within the gel varied with the exposure conditions and the formulation of collagen solution. Gelation induced by exposure to the radiation from an incandescent filament resulted in the formation of a collagen fibril network with thick collagen fibrils present within the gel (Figs 2(a) and (c)). Gelation induced by exposure to heat $\left(37{ }^{\circ} \mathrm{C}\right)$ in the water bath resulted in much finer collagen fibrils (Figs 2(b) and (d)). The thickest collagen fibrils were observed in the gel formed from collagen alpha-modified MEM solution and exposed to the radiation from an incandescent filament (Fig. 2(a)). Positive staining with methyl blue (Sigma,
Dorset, UK) of both the original gels and dehydrated samples from these gels confirmed the presence of collagen in each gel.

To investigate further the influence of exposure condition and formulation of collagen solution on the thermal properties of the gel, calorimetric measurements were performed using a differential scanning calorimeter (DSC), equipped with a refrigerated cooling system. The denaturation temperature $\left(T_{\mathrm{D}}\right)$ was determined as the onset point of the endothermic peak of the DSC profiles (Fig. 3) as this shows when the collagen structure begins to break down. The measurement was carried out on the gels immediately after preparation. Excess liquid on the surface of the gel was removed using a piece of filter paper prior to sealing the gel in aluminium pans. The sample was heated in a nitrogen atmosphere at a rate of $1{ }^{\circ} \mathrm{C} / \mathrm{min}$ from room temperature to $80{ }^{\circ} \mathrm{C}$. Depending on the exposure conditions and the formulation of collagen solution, $T_{\mathrm{D}}$ (Table 1) of the collagen gels varied from 50 to $47{ }^{\circ} \mathrm{C}$. A slightly higher $T_{\mathrm{D}}$ was observed for gels exposed to the radiation from an incandescent filament compared to gels exposed to heat in a $37^{\circ} \mathrm{C}$ water bath.

The presence of fibrils in the SEM micrographs and the values of $T_{\mathrm{D}}$ suggest that these gels are unlikely to be denatured. Thicker collagen fibrils are associated with a slightly higher $T_{\mathrm{D}}$.

\section{CONCLUSIONS}

This preliminary experiment has shown that a sterile non-contact process using the radiation from an incandescent filament can be used to create a simply structured collagen gel from a collagen solution formulated with non-cytotoxic 

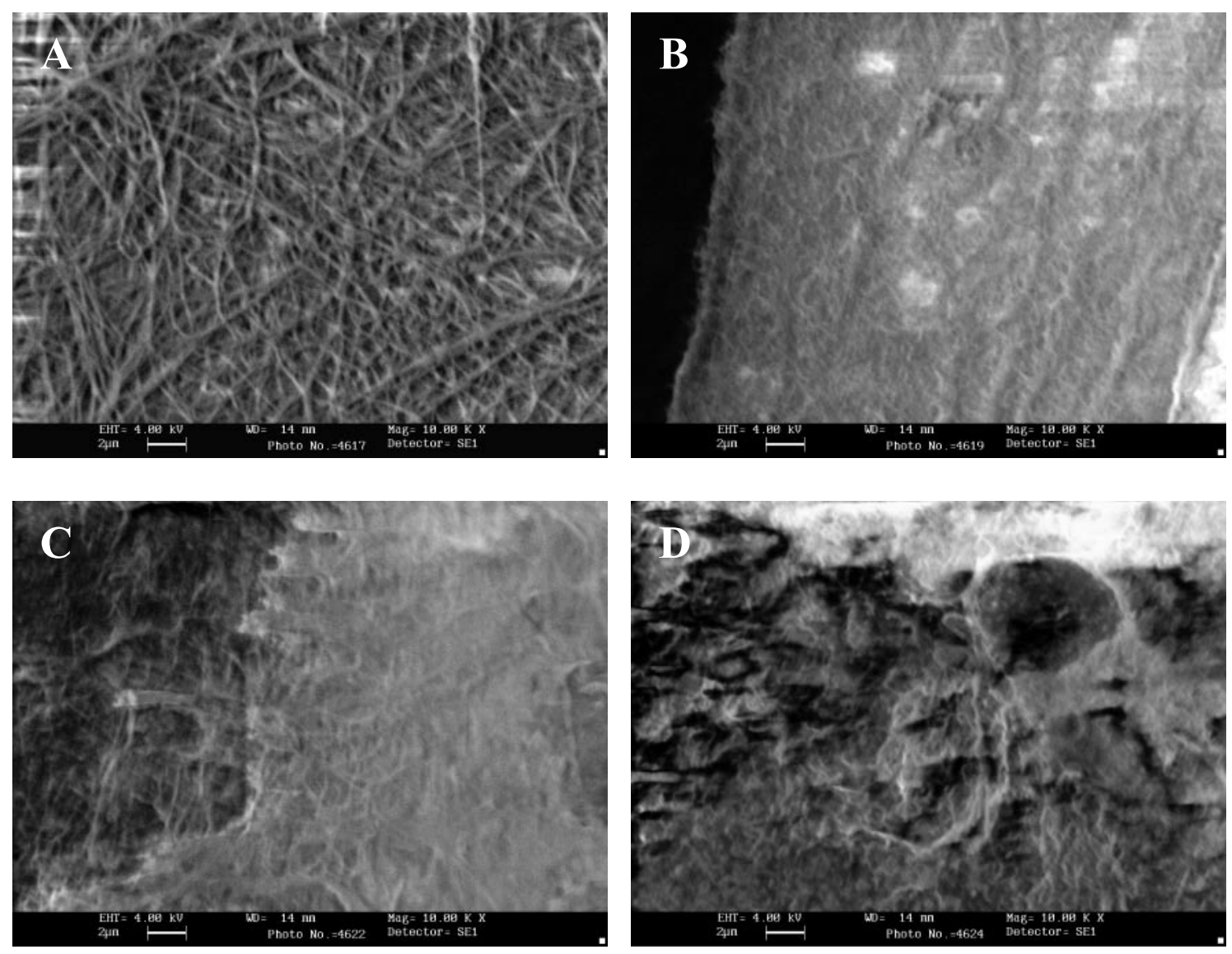

Fig. 2 SEM micrographs of collagen gel prepared using collagen alpha-modified MEM or PBS solutions exposed to radiation provided by an incandescent filament or to heat in a $37{ }^{\circ} \mathrm{C}$ water bath; (a) gel formed from collagen alpha-modified MEM solution by exposure to the radiation from an incandescent filament; (b) gel formed from collagen alpha-modified MEM solution by exposure to heat in a $37{ }^{\circ} \mathrm{C}$ water bath; (c) gel formed from collagen PBS solution by exposure to the radiation from an incandescent filament; (d) gel formed from collagen PBS solution by exposure to heat in a $37^{\circ} \mathrm{C}$ water bath (scale bar $2 \mu \mathrm{m}$ )

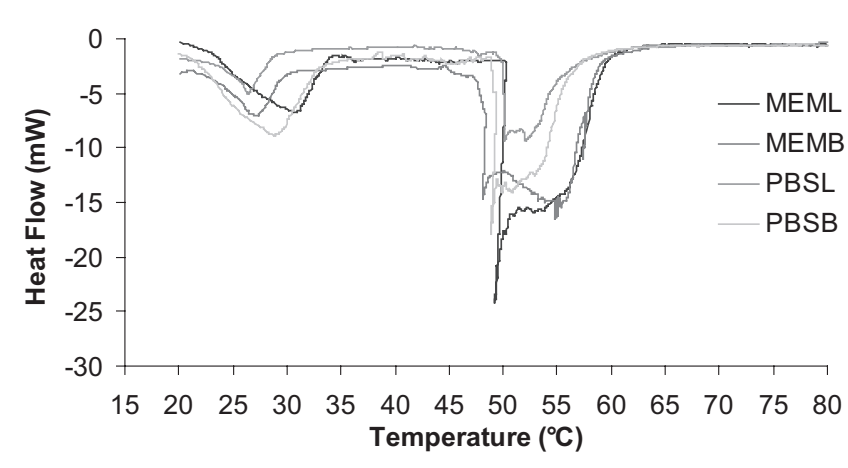

Fig. 3 DSC profiles of gels prepared from collagen alphamodified MEM or PBS solutions exposed to the radiation from an incandescent filament or heat in a $37{ }^{\circ} \mathrm{C}$ water bath. MEML, collagen alpha-modified MEM solution exposed to the radiation from an incandescent filament; MEMB, collagen alpha-modified MEM solution exposed to the heat in a $37{ }^{\circ} \mathrm{C}$ water bath; PBSL, collagen PBS solution exposed to the radiation from an incandescent filament; PBSB, collagen PBS solution exposed to the heat in a $37^{\circ} \mathrm{C}$ water bath.
Table 1. Denaturation temperatures $\left(T_{\mathrm{D}}\right)$ of collagen gels prepared from alpha-modified MEM or PBS collagen solutions by exposure to radiation from an incandescent filament or heat in a $37{ }^{\circ} \mathrm{C}$ water bath. $T_{\mathrm{D}}$ was determined as the onset point of the corresponding endothermic peak on the DSC profiles.

\begin{tabular}{lll}
\hline & Incandescent filament $\left({ }^{\circ} \mathrm{C}\right)$ & $37^{\circ} \mathrm{C}$ water bath $\left({ }^{\circ} \mathrm{C}\right)$ \\
\hline MEM & 50 & 47 \\
PBS & 49 & 48 \\
\hline
\end{tabular}

alpha-modified MEM. Gelation with alpha modified MEM was accelerated when compared with a collagen PBS solution. Methyl blue staining and SEM micrographs confirmed the native fibril structure of the collagen. The DSC results indicated that the gels were not denatured and would be able to support cell growth at $37{ }^{\circ} \mathrm{C}$. The generation of a gel boundary suggests the approach may be applicable 
in a lithography-based rapid prototyping process. Such a process may also allow cell distribution in a matrix promoting cell growth.

\section{ACKNOWLEDGEMENTS}

The authors would like to acknowledge the support of David Smith, Dr Danish Malik, and Ray Reading for their help and access to laboratory facilities and Drs Paul Hourd, Immanuel Sebastine, and Ying Di for their comments on drafts of the manuscript. This work was supported by a Strategic Research Grant of the EPSRC-funded Innovative Manufacturing and Construction Research Centre at Loughborough.

\section{REFERENCES}

1 Hay, E. D. Cell biology of extracellular matrix (Plenum, New York; London), 1981, pp. 385-410.

2 Kleinman, H. K., Klebe, R. J., and Martin, G. R. Role of collagenous matrices in the adhesion and growth of cells. J. Cell Biol., 1981, 88(3), 473-485.

3 Bell, E., Ivarsson, B., and Merrill, C. Production of a tissue-like structure by contraction of collagen lattices by human-fibroblasts of different proliferative potential in vitro. Proc. Nat. Acad. Sci. USA, 1979, 76(3), 1274-1278.

4 Besseau, L., Coulomb, B., Lebreton-Decoster, C., and Giraud-Guille, M. M. Production of ordered collagen matrices for three-dimensional cell culture. Biomaterials, 2002, 23(1), 27-36.

5 Zeeman, R., Dijkstra, P. J., and van Wachem, P. B. et al. Successive epoxy and carbodiimide cross-linking of dermal sheep collagen. Biomaterials, 1999, 20(10), 921-931.

6 Sato, K., Ebihara, T., Adachi, E., Kawashima, S., Hattori, S., and Irie, S. Possible involvement of aminotelopeptide in self-assembly and thermal stability of collagen I as revealed by its removal with proteases. $J$. Biol. Chem., 2000, 275(33), 25 870-25 875.

7 Griffith, L. G. and Naughton, G. Tissue engineering current challenges and expanding opportunities. Science, 2002, 295(5557), 1009-1014.

8 Hutmacher, D. W., Sittinger, M., and Risbud, M. V. Scaffold-based tissue engineering: rationale for computer-aided design and solid free-form fabrication systems. Trends Biotechnol., 2004, 22(7), 354-362.

9 Brinkman, W. T., Nagapudi, K., Thomas, B. S., and Chaikof, E. L. Photo-cross-linking of type I collagen gels in the presence of smooth muscle cells: mechanical properties, cell viability, and function. Biomacromolecules, 2003, 4(4), 890-895.

10 Williams, C. G., Malik, A. N., Kim, T. K., Manson, P. N., and Elisseeff, J. H. Variable cytocompatibility of six cell lines with photoinitiators used for polymerizing hydrogels and cell encapsulation. Biomaterials, 2005, 26(11), 1211-1218.

11 Zhu, Y. K., Umino, T., Liu, X. D., Wang, H. J., Romberger, D. J., Spurzem, J. R., and Rennard, S. I. Contraction of fibroblast-containing collagen gels: initial collagen concentration regulates the degree of contraction and cell survival. In Vitro Cellular \& Developmental Biology-Animal, 2001, 37(1), 10-16.

12 Willits, R. K. and Skornia, S. L. Effect of collagen gel stiffness on neurite extension. J. Biomater. SciencePolym. Edn, 2004, 15(12), 1521-1531.

13 O'Connor, S. M., Stenger, D. A., Shaffer, K. M., Maric, D., Barker, J. L., and Ma, W. Primary neural precursor cell expansion, differentiation and cytosolic $\mathrm{Ca} 2+$ response in three-dimensional collagen gel. $J$. Neurosci. Meth., 2000, 102(2), 187-195. 